popular style with relatively little attempt to argue and document, and second, in a more discursive manner. This format makes it possible to refer back and forth to the two levels of understandingoften a profitable exercise. The development of cellular immunology is accurately traced but a clear statement of the present position is often lacking. For this latter deficiency Burnet cannot be held wholly to blame; he is clearly an avid reader of the literature and in touch with many unpublished new experiments (particularly Australian) in a rapidly moving field; his doctrinaire approach, however, seems to have tempted him to ignore almost completely the phenomenon of cellular cooperation in the production of antibody which is presently so exciting for immunologists. The sort of experiments in which cooperation occurs (particularly between thymus and bone marrow-derived cells) are dismissed somewhat curtly as laboratory exercises, less likely to give significant results than the "experiments of nature" which are presented by the various congenital deficiencies of the immune system in man.

The material in Immunological Surveillance in some ways duplicates what is said in the other book. If anything, it is presented from a more emphatic viewpoint. Burnet seems to be trying to restrain his self-confessed and long-rooted capacity for making generalizations but without much success. We are told in the same paragraph (p. 6) that it is axiomatic (which the Oxford English Dictionary defines as "a self-evident truth") that "transplantation of a spontaneous primary tumour to another host follows the same rules as transplantation of normal skin". Two lines later we find "No biological statement can ever be made in absolutes". Perhaps this is a simple linguistic problem, but Burnet makes much use of the word axiomatic and it is difficult to credit that he always means "it is assumed that".

With this said it must be pointed out that both books abound in brilliant new ideas. Any research immunologist looking for a problem might well browse here, but let him beware of the premises on which Burnet bases his arguments; it is not easy to disentangle fact from the products of Burnet's fertile imagination. There are many instances of Burnet's laconic humour and increasing evidence that he is to be thought of as a humanist first and scientist second (for example, p. 120, Immunological Surveillance).

As biology becomes more diversified and its devotees more bewildered at the range of facts that they are expected to encompass, the numbers of great allrounders like Burnet must steadily dwindle. Although he says that he has avoided the great conundrums of biology -the mechanisms of evolution, the relation between brain and mind and so on-he is avowedly concerned with "immunity, growth, ageing, cancer and autoimmunity" (p. 50, Immunological Surveillance); far more than enough for most men and, in time, too much for any single mind. Burnet's books should be read with awe at their scholarship but not with unthinking belief as ex cathedra utterances, for herein lies both their great strength and their weakness.

A. J. S. Davies

\section{Insect Gametogenesis}

L'Influence des Stimuli Externes sur la Gamétogenèse des Insectes. (Colloques Internationaux du Centre National de la Recherche Scientifique, Tours, 9-13 Septembre 1969.) Pp. 422. (Editions du Centre National de la Recherche Scientifique, 1970.) 64.50 francs.

IT has long been realized that the reproductive activities of insects are not only regulated to accord with the seasons but also limited by nutrition. Only in comparatively recent years has it become understood that reproduction may be controlled by the environment so that the rate of increase in a population is limited to a level that the environment can sustain.

Many examples of the adaptive control of reproduction are brought out in this symposium volume. Many parasitic insects retain and even resorb their eggs if there is a deficiency of hosts (Labeyrie, Onillon). Overcrowding among locusts leads to a change of "phase"; the gregarious migratory phase that results has a lowered reproductive rate (Papillon, Cassier). In ant societies the queen exerts a "psychosomatic" influence on the reproductive activity of the workers: their reproduction is either totally suppressed, or they produce small eggs incapable of development which are used as food for the larvae. In the absence of the queen, normal eggs are laid and, as they are unfertilized, give rise to males (Brian, Passera). The beet moth Scrobipalpa commonly reabsorbs the eggs in the absence of sugar beet; in the presence of the host plant, copulation and ovogenesis are stimulated and this leads to a rapid infestation of the crop (Robert). Effects of this kind are very frequent though not universal among Lepidoptera (Deseö). The various stimuli may promote copulation; the spermatozoa, acting through the sensory nervous system, can then activate the corpora allata. On the other hand, it may be that olfactory stimuli have the same effect (Benz).

Other contributions record the many ways in which reproduction can be influenced by external stimuli. In those Hemiptera, such as the bed bug, which practise "traumatic insemination", it is the arrival of the spermatozoa in the ovary which evokes the gonadotropic secretion of the corpus allatum (Cara- yon). Copulation (Davey) or the presence of an introduced spermatophore (Engelmann) commonly stimulates oogenesis; in cockroaches the presence of a ripening egg capsule in the brood chamber inhibits the ripening of more eggs (Roth). These and other effects, such as the loss of sexual receptivity by the female Drosophila after mating, are generally exercised by way of the endocrine system, and usually via the corpus allatum or the neurosecretory cells in the brain (Merle, Joly). Finally, the deliberate pollution of the environment with "chemosterilants" by human agency can throw the ovary itself into disarray (Landa).

\section{B. WIGGLESWORTH}

\section{Fungal Biology}

Introduction to Fungi. By John Webster. Pp. 424. (Cambridge University: London, November 1970.) 60s; $\$ 10.50$.

IN reviewing and warmly recommending Alexopoulos's Introductory Mycology, Dr Ainsworth" wrote "If de Bary's Morphology and Biology of the Fungi, 1887 , is taken as a standard, a satisfactory modern textbook of mycology has yet to be written, ....". That book has now been written. Professor J. Webster wrote his book with two aims in mind. First, to write an introduction to those fungi which are easily available in the living state and to give some indication of where they can be obtained. Second, to produce illustrations of the kind that a student could make for himself from simple preparations of living material, and to illustrate things which he can verify for himself. Nobody can argue that he has not been eminently successful in achieving these aims. Webster is a rare artist among mycologists and most of the many illustrations in the text are his own, an almost unique feature in modern biological texts. Few students will ever match his excellent line illustrations. It is difficult to single out any for praise, but to suggest that many bear comparison with those in Engler and Prantl's Die Natürlichen Pfänzenfamilien is enough.

The text follows the general purpose scheme of classification proposed by Ainsworth in 1966 and consists of a short chapter on the Myxomycota followed by four chapters on the Eumycota, one on each of the four sub-divisions Mastigomycotina, Zygomycotina, Ascomycotina and Basidiomycotina. Selected common genera from the various orders or families within each sub-division are considered and accounts given of their methods of development, reproduction and dispersal, physiology, nutrition, mating type behaviour and a wealth of other very up to date information such as control methods, if pathogens, fine structure and economic uses.

In a textbook of some 400 pages, 